\title{
What's Intellectual Property Good for?
}

\author{
Michele Boldrin and David K. Levine
}

First version: November 8, 2010

This version: MarchA $\pi \rho i ́ \lambda$ los 8, 2011

\section{Introduction}

Intellectual property may turn out to be among a handful of themes that will accompany us for most of the XXI century, shaping our economic future and maybe not just that. In spite of having been around - with ups and downs - since the times of James Watt, the controversy over intellectual property started anew in the second half of the 1990s and is likely to grow, in both intensity and relevance, during the decades to come. Behind this renewal of interest we see three main reasons: (i) the emergence of a global economy in which, thanks to the mechanization of a growing number of physical production processes and the growth in average human capital, the role played by creativity and innovation in the production of value added increases at a fast rate; (ii) the increase in the level and the extension in the scope of intellectual property protection that started, in the USA, during the Reagan administration, continued worldwide with the establishment of the WIPO and shows no signs of relenting, yet; (iii) the emergence, after almost a century of apparently unanimous consensus within the legal and economic professions, of a dissenting and heterogeneous set of opinions questioning the legal foundations, the practical usefulness and the internal economic coherence of the existing system of intellectual property.

Our contribution to this debate has been threefold. We pointed out, first, that the standard (so called "Schumpeterian") theory of innovation is grossly at odds both with history and with statistical facts. In particular: we pointed out the absence of almost any example of innovative industry in which the "creative destruction" process takes place according to the predictions of that particular model. Secondly, we brought to the forefront a point of view, rooted in classical economic theory, reconciling three main empirical findings:

(i) The existence of widespread and sustained innovation, over time and across sectors and countries, in the presence of imitation and competition, i.e. in the absence of any form of patents and copyright;

(ii) The lack of any convincing empirical evidence that monopoly, which intellectual property helps creating when and where it is adopted, has had the effect of increasing the rate of innovation by any measurable amount;

(iii) The existence of a small but important set of very costly innovations that are not undertaken under competition, requiring public subsidies to be carried out. 
Third, we have contributed to a growing literature explaining not only why imitation and competition can go hand in hand but also, and more importantly, why reinforcing intellectual property often reduces innovation and only increases rent-seeking and wasteful transaction costs.

Contrary to Paul David's "humorous" remark, what we have done in our research on this issue is scarcely an example of "modern economics" (whatever that may be) theorizing something obvious after the fact. Rather, most of our research has meant to be a reminder - to the forgetful very many among contemporary economists - that established theories and models of innovative activity were, and are, orthogonal to the observed facts, and that a perfectly good theory explaining the evidence has been available since at least the times of Alfred Marshall. It only needed to be reevaluated and developed in the light of recent advances in economic theory. Interestingly enough, what we considered a rather straightforward contribution - i.e. facts contradict established theory but here is a piece of classical economic theory matching the facts quite well - has been received first with incredulity (i.e. "You must be wrong, there cannot be sustained innovation under competition"), then with a mixture of hostility and disdain of which we have two nice examples in Foray's contribution to this volume and in the review by Scherer he quotes approvingly. But this controversial matter we should leave for the end. Between here and there, we first briefly summarize our theoretical viewpoint and then the main empirical evidence that, in our view, supports it. As we go along, we also try addressing some of the criticisms raised against our research since our book, Against Intellectual Monopoly, started to circulate about 3 years ago.

\section{What is all the fuss about?}

For all the opposing emotions and stern accusations the public debate over intellectual property is stirring, it seems both those in favor of strengthening and those in favor of weakening existing protection agree that intellectual property laws need to strike a balance between providing sufficient incentive for creation and the freedom to make use of existing ideas. Put it differently, both sides agree that intellectual property rights are a "necessary evil" that fosters innovation, and disagreement is over where the line should be drawn. For the supporters of intellectual property, current monopoly profits are barely enough; for its enemies currently monopoly profits are too high. In fact, one is tempted to say, for many "enemies" of intellectual property, profits are always too high as long as they are positive and for many "friends" of intellectual property, property are always barely enough, if they are enough at all. Among other things, we do not believe that trying to figure out if a very elaborate system of property rights - such as patents and copyright are - is or not socially useful by measuring if the profits it supposedly generates are or are not high

enough ex-post, is the right way to go. Among the reasons why such a procedure is likely to produce inconsistent results, are the following ones: that profits, or lack of them thereof, in a line of business in which intellectual property is allowed may easily be due to factors other than intellectual property per se; that the "appropriate" level of profits, in any given line of business, is far from obvious most of the times; and that, last but not the least, the way in which a certain allocation of property right 
may be socially damaging, or beneficial, has often very little to do with the measured level of profits one obtains in this or the other industry, if at all. In summary: better think at something else other than "profits" to figure out if intellectual property makes sense or not as a social arrangement. Our proposed candidate being the growth over time of consumer welfare or, which is roughly the same, the growth rate of labor and total factor productivity, sector by sector. Surprisingly enough, there is still exceedingly little research attempting to do this, i.e. trying to use sound models of innovation to evaluate empirically which relation exists between intellectual property and measurable economic growth.

We should also make clear that the often heard statement according to which, in the absence of intellectual property protection, we would have to appeal to the benevolence of innovators, or to their desire to cooperate, to keep the stream of innovations flowing is just plain nonsense. When we advocate the abolition of patents and copyright we do not do so because we are of the view that innovators should work out of benevolence. Certainly few people do something in exchange for nothing. Creators of new goods are not different from producers of old ones: they want to be compensated for their effort. As far as we are concerned, innovators are like any other entrepreneur: they want to maximize profits from whatever business they are involved in, given the rules of the games and their capabilities. However, it is a long and dangerous jump from the assertion that innovators deserve and want compensation for their efforts to the conclusion that patents and copyrights, that is monopoly, are a good way of providing that reward. There are many other ways in which innovators may be and are rewarded, which are worthy of both theoretical and empirical investigation and are, instead, being neglected: competitive rents, first mover advantages, collateral sales, reputational effects, public prizes and subsidies, trading on the informative advantage the innovation provides and, finally, trading of the innovation itself. Hence, and again, since innovators may be rewarded even without patents and copyright, we should ask: is it true that intellectual property achieves the intended purpose of creating incentives for innovation and creation that offset its considerable harm?

The same observation applies to those arguing that when some industry or trade is able to innovate even in the absence of formal intellectual property protection, this is due to special institutional arrangements that are not applicable in general. This statement is anti-historical, to start with: in the absence of intellectual property, which was extended to them only in recent years or decades, a very large number of innovative industries have been functioning very well for decades, centuries and even millennia. To name the most visible ones: agricultural innovations have been patentable, de facto, only since the 1970 s, while, until the end of WWII, the development of the chemical and pharmaceutical industries has taken place essentially without patentability for its products. The software industry, arguably the most innovative during the last half century, developed also in the complete absence (according to many practitioners, including Bill Gates, "thanks" to the complete absence) of any form of intellectual property, which was extended to it, progressively, only during the last two decades. The empirical evidence available shows that, in all these industries, the rate of technological innovation has certainly not increased - and 
it may well have decreased - since patents were allowed. The financial industry is, for any practical matter, still free from copyright and patents while, in spite of its many and even dramatic regulatory failures, it keeps innovating at a remarkable speed. The list can be substantially extended. On the side of copyright the same is true, for example, for classical music until about the second half of the XIX century and the US book publishing business until the end of the same century. Claiming that special circumstances explain the open source or the fashion industries of the XX and XXI centuries, amounts to ignoring the best available historical evidence while revealing to be unable to explain the facts. The "exceptionality argument" is also theoretically confused insofar as it fails to recognize that various among the mechanisms described as "special" are, in fact, quite general and applicable to plentiful trades. As this point requires a bit of additional elaboration we will return to it when discussing the open source software experience in section 5 .

Begin by asking: why should creators have the right to control how purchasers make use of an idea or of a new good? This gives creators a monopoly over the idea. We refer to this right as "intellectual monopoly," to emphasize that it is this monopoly over all copies of an idea that is controversial, not the right to buy and sell copies. The government does not ordinarily enforce monopolies for producers of other goods. This is because it is widely recognized that monopoly creates many social costs. Intellectual monopoly is no different in this respect. The question we address is whether it also creates social benefits commensurate with these social costs.

This may be the appropriate point to discuss another, often heard, criticism, according to which "monopolistic competition" is the rule of the game in almost every industry, hence what difference does a patent or a copyright make? It makes a big difference: in the market for shoes or bread competing firms freely select where to position themselves. If one likes to position very close or very far from its competitors, there is no legal constraint to prevent such a choice from being implemented. When patents and copyrights enter the scene the situation changes: one can no longer choose freely how to compete with the insiders. The world of free monopolistic competition is an always changing one in which your competitors may come extremely, even unpleasantly, close to you and beat you, for example, just because they use a cheaper delivery system. In the world of legal monopoly this is prohibited by law, for two decades in the case of patents and for pretty much ever in the case of copyrights. Thereby the qualitative difference. Is it also quantitatively important? We believe it is and the data we have brought to bear on the issue, suggest so. We may have made the wrong calculations and we may have looked at the wrong facts, but we need to be proved wrong with facts and data. Just arguing that "cosi" fan tutte" is not enough.

A number of critics have argued that our use of the term "monopoly" to define the effect that intellectual property has on the markets where it applies, is too strong when applied to copyright because the latter seeks to protect "expression" of ideas, not the idea being expressed. Maybe it is too strong, but, in the English vocabulary, we cannot find a better term describing a legal right that allows sellers of, say, books to determine what lawful buyers of their product are allowed to do with it. In particular, how else to define the following facts? Publishers of academic journals can 
prevent the original authors of the articles from circulating copies of the same, even for free. Citations from books, or music, or movies that were legally purchased cannot be longer than a few lines or seconds without additional payments to the original publisher, even if such citations are obtained through legal and widely available technologies. As a third example consider the recent Google Book disaster - born as Google Print, then morphed into Google Books Search - in which publishers of books that had been legally purchased, at library rates, by libraries around the world have successfully challenged the right of such libraries to enter into cooperation with Google in order to digitize those books and make them searchable and usable on line, for free, through Google's proprietary technology. Matter of fact a "monopoly" is, in economic parlance, the exclusive right to sell/produce a certain object of service.

A further point of discussion is that proposals to either abolish or greatly reduce intellectual property would be infringing on long established rights that are protected, among other, by constitutional provisions. The U.S. Constitution allows Congress "To promote the progress of science and useful arts, by securing for limited times to authors and inventors the exclusive right to their respective writings and discoveries." Our perspective on patents and copyright is a similar one: from a social point of view, and in the view of the founding fathers, the purpose of patents and copyrights is not to enrich the few at the expense of the many but only to promote innovation and creativity. Nobody doubts that J. K. Rowling and Bill Gates have been greatly enriched by their intellectual property - nor is it surprising that they would argue in favor of it. But common sense and the U.S. Constitution say that these rights must be justified by bringing benefits to all of us, which gets us back, once again, to the issue of evidence we obsessively stress: where is it?

This is a point that deserves stressing: in the current debate one is repeatedly forced to face the claim that, should intellectual property be reduced or abolished, the income of innovators would be reduced, sometime substantially. The latter observation is then used to imply, automatically, that this would bring about an end to innovative activity. This is an absolute non sequitur as it ignores that what matters is the absolute value of the rent accruing to the innovator compared, on the one hand, with the fixed cost of the innovation and, on the other, with the rent that would accrue to him in his alternative forms of employment. In other words: what matters is the opportunity cost of innovators and not how large a share of the social value of their innovations they take home, a theme continuously, and erroneously, stressed in the industrial organization literature. To clarify this, apparently forgotten, point let us turn to a bit of economic theory.

\section{Does Intellectual Monopoly Increase Innovation? Theory}

From a theoretical point of view, intellectual monopoly may both increase and decrease innovation: it provides more revenues to those that innovate, but also makes innovation more costly. Innovations generally build on existing innovations. While

\footnotetext{
${ }^{1}$ U.S. Constitution Article 1, Section 8. The U.S. Constitution, not being copyrighted, is online at various places, such as http://www.law.cornell.edu/constitution.
} 
each individual innovator may earn more if he has an intellectual monopoly, he also faces a higher cost: he must pay off all those other monopolists owning rights to existing innovations. In other words: as a matter of theory in a general equilibrium where monopoly is the rule, while it is unambiguous that consumer surplus will be greatly reduced relative to one where competition is the rule, it is not obvious at all that there would be a higher aggregate level of innovative activity. In fact, we have used simple and natural models to show that, in the limit, such a world converges to a Nash equilibrium where innovation has probability zero, (Boldrin and Levine [2005a]).

Again and along the same lines: from a theoretical point of view, once the monopoly power is taken away innovator's rents will decrease as competitors move in and productive capacity expands much faster than under monopoly, as one would expect in a competitive industry. Still, as Marshall (but even Smith and Ricardo before him) taught us, rents due to the existence of limited capacity will be dissipated slowly as entry, imitation and competition take place over time and not instantaneously and without cost. Plentiful static theories of innovation, adopted in the industrial organization literature, abuse of the competitive equality of prices and marginal costs by ignoring that it is reached, under free entry, only in the long run equilibrium of the industry. There is no theoretical reason to believe that the timeintegral of rents accruing to innovators along the path to such long-run position could not cover their opportunity costs, hence motivating them to go ahead with the innovation in any case. Again, the matter is empirical and it can be addressed only by looking at different industries and the rate at which innovation increases or decreases, when monopoly power and concentration increases or decreases. This point has been made repeatedly and, again and again, it has been ignored by the followers of the "Schumpeterian" model. They seem unable to comprehend that the theoretical tool they adopt is just an extremely special case of the "Marshallian" one; a special case that obtains when productive capacity can be accumulated instantaneously and at zero cost to anyone else but the innovator.

A very special "special case" indeed it is, as can be easily grasped with a bit of reflection. In the baseline model of innovation adopted by most new growth and industrial organization theorists, in fact, absent intellectual property the competitive equilibrium would be one of pricing at (variable) marginal cost, implying equilibrium losses equal to the fixed costs. This prediction evaporates as soon as one is willing to admit that even imitators would have to pay some fixed cost of entry, for very small say $f$ - that the latter could be compared to that - say $F \gg f$ - of the innovator. It is trivial to see that, in the latter case, the payoff to the imitators when goods are sold at marginal cost is $-f$, making the choice of entering the industry dominated by that of staying out and doing nothing, as the latter yields a payoff of $0>-f$. Under such assumptions, in fact, the only sub-game perfect equilibrium of the sequential game in which the innovator first chooses to either innovate or not and then the imitator chooses to either imitate or not, is one in which the innovator innovates while the imitator stays out, thereby leaving the innovator with full monopoly profits even in the absence of any intellectual property protection! This equilibrium is still there even 
in the limit case in which $f \rightarrow 0$ while $F$ remains positive. Only, in this case, the sequential game in question has a second sub-game perfect equilibrium in which, just out of spitefulness, the imitators enter the industry purely to force the innovator into making losses of $-F$, as their payoff of zero is identical to what they would receive by staying out. In other words, as a matter of theory, the so-called "Schumpeterian" theorizing about innovation and growth seems to rely more on individual spitefulness than anything else.

Let us move on to consider other theoretical aspects of the matter. Expecting strong competition from imitative firms a potential innovator would have lower incentives to innovate if the industry in which it operates were such that the other firms do not have the ability to innovate by themselves. In other words, if our putative innovator were, for whatever reason, the undisturbed leader of the industry under consideration and the other players could always and only choose between imitating and doing nothing, then it would be reasonable to innovate as little as possible to keep the leadership, as the competitors are capable of competing only by imitating and catching up. As a matter of theory, but also as a matter of common sense, things can easily be different, i.e. in a competitive industry there may be more than one firm capable of innovating at any given point in time and competitor can, suddenly, jump ahead of a passive and non-innovative leader, leaving it in the dust. To the extent that we are not living in a world of "once-and-for-ever" innovations, and to the extent in which, in any given industry, there is no designated forever leader, the faster dissipation of the innovator's rents together with the higher risk of losing the leadership because other firms may innovate, would provide an incentive to try keeping the lead by innovating faster. Again, which of the two outcomes is more likely in reality is a matter of empirical evaluation, little of which seems to interest applied industrial organization researchers.

There are other dimensions along which theory per se is unable to provide an answer but into which the theoretical contributions of the last two decades have shown it worth focusing our empirical attention. A number of economic historians, Douglass North and his followers foremost among them, have argued that the great acceleration in innovation and productivity we associate with the Industrial Revolution was caused by the development of ways to protect the right of inventors, allowing them to profit from their innovations. ${ }^{2}$ Central among such ways was the attribution of patents to inventors, and their upholding either by Parliament or by the courts. Relative to the very poorly defined contractual rights of pre-seventeen century Europe, plagued by royal and aristocratic abuses of property and contracts, there is no doubt that allowing entrepreneurs a well defined, if temporary, monopoly over the fruits of their inventive effort was a major step forward. Even monopolistic

\footnotetext{
${ }^{2}$ To learn more about Douglass North's views one may want to start from North [1981, 1991]. It should be noted that North does not subscribe to a naïve view of the evolution of property rights according to which they become progressively more "efficient" or just simply "better" as time goes on and the economy develops. Being aware of the fact they are, more often than not, determined by rent-seeking agents within a political game, North is careful at pointing out that the system of property rights one often faces is substantially inefficient or inefficiency-inducing along more than one dimension.
} 
property is much better than a system that allows arbitrary seizure by the rich and powerful. This does not, however, contradict the claim according to which widespread and ever growing monopolistic rights are not as socially beneficial as well defined competitive property rights. To put it differently, about four centuries ago, as Western societies moved away from post-medieval absolutist regimes, the establishment of patents constituted a step forward for the creation of a system of property rights that favored entrepreneurship and free market interaction. By the force of the same reasoning, the abolition of patents and of the distortionary monopolistic rights they entail may well result, now, in an analogous boost to entrepreneurial effort and technological change. Once again, as a matter of available theories one cannot safely conclude one way or another. Only careful historical and institutional analyses of as many case studies as possible, of which those this volume contains are excellent examples, will allow us to provide, eventually, an answer to this question. Point is, though, that without the theoretical contributions published since the middle 1990s, which have allowed us to question the established consensus, this kind of questions could not even be asked.

The contribution that the Neo-Institutional approach may still provide to this debate raises a number of relevant issues we unfortunately cannot address here. We would like, though, to point out one thing: patents are by no means the only legal instruments allowing for contractability of ideas and for the creation of a maket for technology transfers. Beginning with the pathebreaking work of Jack Hirshleifer in the early 1970s, it has become clear that economically valuable information can be traded in the absence of patents and under condition of competition or nearly so. There is no prima facie evidence, either theoretical or empirical, for the claim that the disappearance of patents would increase transaction costs associated to technology transfer. Most likely, it will reduce them insofar as it will reduce incentives for rentseeking, defensive patenting, submarine patenting and all the gigantic legal costs these practices have brought upon us. In summary, well defined and protected private property of own ideas does not require monopoly over them pretty much in the same way that private property of our own cars does not require the two of us becoming the only motorized citizens of the USA.

Theory, finally, suggests also that small countries with low IP protection should witness a surge in the inflow of IP-related investment after their IP protection is increased, as they capture investments from other countries where intellectual monopoly is protected less. The latter is a particular kind of "zero-sum game"3 that, unfortunately, appears to have gone beyond a mere theoretical possibility. What is less obvious, is what the outcome will be once every country adopts the same high degree of IP protection. Leave aside the more or less terrifying scenarios of escalation - in which countries out-do each other trying to allure IP-related investments by progressively increasing their local protection of intellectual monopoly. It is still worth asking if a world where everyone has the same degree of IP protection as, say, the US currently does is a world with a higher or lower rate of innovation and a higher or lower social welfare than a world with much less IP protection.

\footnotetext{
${ }^{3}$ In fact, negative-sum insofar as it increases lobbying efforts and related wasteful transaction costs.
} 


\section{Does Intellectual Monopoly Increase Innovation? Facts}

Theory gives ambiguous answers to most of the important questions we ask, so let us look at evidence, supported by a bit of statistical common sense. Recognize, first, that intellectual monopoly is a double-edged sword. The existence of monopolies increases the cost of creation. Because this is a fact regularly ignored in the public debate let us try again to bring it to the forefront with a brief list of examples:

- Boulton and Watt's steam engine patent most likely delayed the industrial revolution by a couple of decades.

- Selten's automobile patent set back automobile innovation in the United States by roughly the same amount of time.

- The Wright Brothers airplane patent forced innovative work on airplane technology out of the United States to France for a decade or so.

- The patent system of England and France forced the chemical industry to move to Germany and Switzerland, where chemical patents did not exist or were much weaker.

- When Verdi gained copyright over his works he stopped producing new works. More generally, there is no evidence that the adoption of copyrights stimulated the creation of classical music.

- As various have documented, the explosion of patents that followed the patentability of software code has most likely contributed to slow down the rate of innovation in this industry.

Given the continued extension of patent protection to new areas - business practices and computer software, for example - one might hope to find very strong evidence, in recent data, that the introduction of patent protection has lead to a substantial increase in innovation. These hopes, alas, are not to be fulfilled: it is already apparent that the recent explosion of patents in the U.S., the E.U. and Japan, has not brought about anything comparable in terms of useful innovations and aggregate productivity. This we asserted a few years ago, while working on our book, and it is even more readily apparent today, in the midst of the Great Recession. The patents' explosion that started in the late 1980s did not bring about any sustained increase of the aggregate productivity growth rate of the USA, the EU or of Japan. In fact, as far as standard aggregate measures of productivity are concerned (i.e. labor and total factor productivity) they have been doing worse recently, on average, than during most previous decades. Furthermore, if one looks carefully into the data, one notices that the sectors that most have contributed to the growth in the aggregate productivity of advanced economies during the $1980 \mathrm{~s}-2010$ period - i.e. retail and distribution, finance, insurance and real estate, constructions, information technology - were characterized by a very low rate of effective intellectual property protection, relative to the rest of the economy, when the bulk of their innovative contribution took place. The aggregate evidence, in other words, does not support the claim that strengthening, as we dramatically have, the level of patent protection will lead to substantial improvements in our growth rate. To this fact we should add that, while there is no hope of finding evidence supporting the claim "more patents = 
higher productivity" in recent aggregate data, also the historical evidence provides little or no support to this claim. ${ }^{4}$ Let's therefore move on to summarize briefly what we have learned from more disaggregated industrial or case studies of the last few decades.

\subsection{Patents and Innovation in the $20^{\text {th }}$ Century}

A number of studies have attempted to examine whether introducing or strengthening patent protection leads to greater innovation using data from post WWII advanced economies. We have identified twenty three economic studies that have examined this issue empirically. ${ }^{5}$ The executive summary: they find weak or no evidence that strengthening patent regimes increases innovation; they find strong evidence that strengthening the patent regime increases ... patenting! They also find evidence that, in countries with initially weak IP regimes, strengthening IP increases the flow of foreign investment in sectors where patents are frequently used.

The authors who find the strongest effect on innovation of increased patent protection are Kanwar and Evenson, and Lo. The latter examines the 1986 reform in Taiwan, while the former use time series data from a cross section of countries to regress $R \& D$ as a fraction of GDP on various variables including a qualitative measure of IP protection. Both sets of results are worth examining a bit more closely than the rest.

Lo finds increased innovation by Taiwanese inventors as measured by R\&D expenditure and by the number of U.S. patents they were awarded. However, given the worldwide surge in U.S. patents about this time and the fact that the number of Taiwanese patents awarded to these same inventors did not much increase, we can neither reliably conclude that the effect of the 1986 law was an increase in innovation, nor a jump in aggregate or sectorial productivity. What the reform certainly did, and Lo documents this convincingly, was to increase the number of patents awarded to Taiwanese firms, especially in the U.S., which is altogether not surprising. Lo himself points out that the main channel through which the Taiwanese reform had a positive effect was by fostering foreign direct investment in Taiwan especially in those sectors in which patents are widely used.

\footnotetext{
${ }^{4}$ Apart for the substantial amount of historical evidence surveyed in our book and based on dozens of independent studies, the reader interested in learning more has got a plenty of good books available. A few titles to start from are Epstein and Maarten [2005, eds.], Khan [2005, Chapter 2], Landes [1969] and Landes [1998]. A recent and fairly unbiased synthesis of the historical literature concerned with the impact of patents on the Industrial Revolution and inventive activity during the $18^{\text {th }}$ and $19^{\text {th }}$ century, McLeod and Nuvolari [2006], concludes by saying "However, it would be wrong to assume that the emergence of patent systems played a critical or determinant role in such a transition. The evidence discussed in this paper has shown that the institutional arrangements supporting inventive activities in this historical phase were extremely variegated and sophisticated. [...] In other words, the roots of western industrialization seem to have been wider and deeper than the emergence of modern patent systems."

${ }^{5}$ For a detailed analysis of these empirical studies we must refer the reader to our book. The data about patents mentioned below come from the 2003 Annual Report of the USPTO, which can be found on line at //www.uspto.gov/web/offices/com/annual, additional basic data is from www.cms.hhs.gov.
} 
This is an important point, which deserves a separate comment as we already mentioned at the end of section 3 . In a world in which strong patent protection in some countries co-exists with weak protection in others, a country that increases patent protection should observe an increase in the inflow of foreign investment, especially in those sectors where patented technologies are used. Profit maximizing entrepreneurs always choose to operate in those legal environments where their rights are the strongest. In the U.S., for example, economists and people with common sense alike, have long argued that the policy of offering tax incentives and subsidies to companies that relocate in one state or another is not a good policy for the United States as a whole. Nobody denies that, if you provide a company with high enough subsidies and tax incentives, it will probably take them and relocate to your state, at least temporarily. The problem is that, after you do so, other states will respond by doing the same, or more. In the ensuing equilibrium, the total amount of investment is roughly the same as when no one was offering a subsidy, but everyone is now paying a distorting tax to finance the subsidy. When capital moves freely across countries, the very same logic applies to the international determination of IP rights. In what economists call the Nash Equilibrium of this game, it is obvious that patent holders prefer to locate in countries with strong IP laws. This increases the stock of capital in the receiving country and reduces it everywhere else, especially in countries with low IP protection. Hence, absent international cooperation, the strong incentive of most countries to keep increasing patent protection, even in the absence of lobbying and bribing by intellectual monopolists.

As for the study by Kanwar and Evanson, they have data on 31 countries for the period 1981-1990. Using two 5 year averages they find support for the idea that higher protection leads to higher R\&D as a fraction of GDP. Their measures of IP protection do not always seem to make sense, but this is not the proper place to engage in a statistical debate. There are five levels of IP protection and R\&D as a fraction of GDP ranges from a ten year average of $.231 \%$ in Jordan to $2.822 \%$ in Sweden. They find that increasing IP by one level raises R\&D as a fraction of GDP between $0.6 \%$ to $1.0 \%$. As before, the most favorable interpretation of this result is that countries offering higher levels of IP protection also attract investments in those sectors in which R\&D and patents are most relevant. A less favorable interpretation of this result, instead, points out that Kanwar and Evenson have forgotten to include a main determinant of the ratio of R\&D to GDP: that is, market size as measured by GDP. The most elementary theory of innovation, either under competition or under monopoly, shows that the innovative effort is increasing in the size of the market, and that large and rich countries will invest a larger share of their GDP in R\&D compared with small and poor countries. Putting Kanwar and Evanson's data together with GDP data from the 1990 CIA World Fact Book, we find that a 1\% increase in the size of a country as measured by GDP increases the ratio of R\&D to GDP by $0.34 \%$.

It is interesting to looks at the residual error that is left over after we predict the ratio of (the logarithm of) R\&D to GDP from (the logarithm of) GDP. Sorted by IP level we find 


\begin{tabular}{|ll|}
\hline IP Level & $\begin{array}{l}\text { Average } \\
\text { Residual }\end{array}$ \\
\hline $\boldsymbol{0}$ & -0.95 \\
\hline $\boldsymbol{I}$ & -0.46 \\
\hline $\boldsymbol{2}$ & 0.20 \\
\hline $\mathbf{3}$ & 0.20 \\
\hline $\boldsymbol{4}$ & 0.10 \\
\hline
\end{tabular}

What does this show? The question is whether increasing the IP level leads to an increase in the residual. Moving from level 0 to 1 and from level 1 to level 2 this is true, but not moving from 2 to 3 or 3 to 4 . In other words, once you control for market size, higher IP protection increases the $R \& D / G D P$ ratio at the very low levels, but becomes uncorrelated with the $R \& D / G D P$ ratio at any level of IP protection equal to 2 or more in the Kanwar and Evenson scale. This reinforces the idea that what we are seeing is primarily the effect of foreign investment. Among poor countries with low IP protection, increases bring in more foreign investment and raise R\&D. In richer countries with high levels of IP, foreign investment is not an issue, and increases in IP have little or no effect on innovation.

All the empirical studies we considered in our book were either published or completed before the year 2006, hence one may reasonably suspect that more recent evidence could show different, even opposite, results. Indeed, if institutional changes, such as the strengthening of patent's laws, are slow to implement and even slower to make their effects felt, it is not unreasonable to expect that statistically measurable beneficial effects of intellectual property reforms would have to wait for a decade or so to be seen. It is therefore relevant to point out that the Paper and Proceedings of the American Economic Association published, in 2009, a group of papers contributed during the annual meetings of the latter that had, as their central piece, the summary of a vast empirical work by Josh Lerner (Lerner [2009]) documenting the negligible, possibly negative, impact of strengthening patent protection on innovative activity. Let us quote directly from the conclusions of the extended working paper version of the same article

"This paper examined the impact of changes in patent policy on innovation. Rather than analyzing a single case, I studied 177 of the most significant shifts in patent policy across sixty countries and 150 years. Adjusting for the change in overall patenting, the impact of patent protection-enhancing shifts on applications by residents was actually negative, whether filings in Great Britain or domestically were considered.

The lack of a positive impact of strengthening of patent protection on innovation is a puzzling result. Not only does it run against our intuition as economists that incentives affect behavior, but also runs counter to the findings in the "law and finance" literature that stronger property rights (e.g., those giving equity-holders more prerogatives) encourage economic growth." 
For the time being, we rest our empirical case here. Should additional, better and more convincing empirical research be made available that proves the opposite is true, we are ready to change our minds. ${ }^{6}$

\section{Abolition}

Defenders of intellectual monopoly like to portray our position as careless and somewhat silly or, at least, naïve. This is, after all, a simple but somewhat cheap way to avoid having to debate the intellectual substance of what we claim. At the same time, defenders of intellectual property like to portray the latter as a powerful and beneficial medicine for an unavoidable and dangerous disease: the highly hypothetical "market failure" according to which there would be none, or little, innovation absent intellectual property. We call the alleged market failure "highly hypothetical" because, as we have briefly illustrated in sections 3 and 4 , the theoretical model implying such failure is a shaky special case of the general competitive model for which such failure is far from obvious and, more importantly, because there is practically zero evidence of such widespread failure taking place in practice. While we keep waiting for substantive arguments showing why we are wrong along the two dimensions just mentioned, let us consider some of the critical shots aimed at our arguments.

Why do we preach abolition of intellectual property instead of advocating this or that reform, this or that improvement? We already showed the logical flaws in the theoretical diagnosis supporting the prescription: the underlying economic theory predicts that we should observe monopolies everywhere, even in the absence of intellectual property. Because we clearly do not, it is reasonable to wonder how well grounded the underpinning hypotheses are. A vast literature, which we have not mentioned here but is surveyed in our book, documents that the medicine of intellectual property has serious side effects and other scientific studies have found at best weak evidence of temporary benefits. Further, all available studies show that in those circumstances in which the patient was not taking the medicine, there was no evidence of the illness coming back. Given all this evidence, would you employ such a drug on an otherwise healthy patient? Perhaps not, unless the illness was clearly visible and proved to be life threatening. Under such circumstances, is it really so naïve and illogical to claim that, maybe, taking the patient off this dangerously addictive drug may be an option worthy of consideration? These are the reasons why we claim that, "on the basis of the present knowledge", progressively but effectively abolishing intellectual property protection is the only socially responsible thing to do. Evidence has accumulated during the last fifty years leaving little doubt about the damaging effects of current intellectual property laws. At the same time, legal, economic, and business know-how has also accumulated about how markets for

\footnotetext{
${ }^{6}$ We cannot help but pointing out here that the same symposium contains also Boldrin and Levine [2009], where we present a simple theoretical model of competitive invention, which is consistent with our version of a marshallian model of a competitive and innovative industry and capable of solving the puzzle. Contrary to the standard model, in our strengthening patent's protection leads to fewer, faster and smaller inventions and to a reduction of the aggregate inventive effort, which is exactly what the micro and macro data studied, among other, by Lerner, repeatedly and systematically show.
} 
innovation operates without intellectual monopoly. To rule out abolition a priori would be no more sensible now than it would have been to rule out the abolition of tariffs and trade barriers fifty years ago, when the trade liberalization process that has given us prosperity and globalization began. For a long time, the individuals and firms that profited from trade barriers argued that these increased the wealth of the nation, defended homeland companies and jobs, and that abolishing them would lead to a disaster for many sectors of our economy. It took a while to realize this was not true, and that trade barriers were nothing more than rent-seeking devices, favoring a minority and dramatically hurting the overall economy and everyone else, beginning with low income consumers. The same is now true of patents and copyright.

Which leads us to address, albeit very briefly, a concern raised by a number of intelligent critics of our position: that we grossly overstate the positive impact competition may have had, or would have, on innovative activity. Again, this may well be true, but there is no empirical evidence whatsoever in the literature that this is the case. In our book we provide dozens of examples of competitive industries that are highly innovative and that are so because they are open to free entry and competition. The list goes from the very important ones - i.e. software, for a long time and still now in the ever expanding OSS segment, the financial industry, the whole of agriculture until the $1970 \mathrm{~s}$, the chemical and pharmaceutical industry until WWII to the somewhat secondary or even marginal - the fashion and pornography industries, for example - or, for that matter, the most dynamic industry of the 1990s: retail distribution 7 . In their discussion of competitive innovation, supporters of intellectual property have always avoided discussing such examples choosing to focus, instead, on the fringe cases such as academic research where the claim that other types of incentive mechanisms (revealing to be first and claiming priority, group recognition, and so on) are certainly in place. Foray's contribution to this volume makes no exception to this disappointing habit. He spends most of the article discussing those he considers as fringe cases, trying to convince himself and the reader that what happens in the OSS or in the fashion business is somewhat special, instead of asking: why has the financial industry been so innovative for a century or more without the use of any intellectual property? How about the agricultural sector?

Even when discussing the allegedly fringe cases, such as the fashion and design industry, Foray seems to be missing the mark almost completely. So, let us consider for a moment the argument according to which what drives the continuous innovation in the fashion and design businesses is a very unique property of their goods, which he labels as "positional" and lead to the assertion that "I can let you copy me because I have already moved on to something else". This may well be the case with the very high end of the fashion business - even if Gucci or Dior would certainly not mind to be able to produce and sell a few hundreds of thousands more of their new shoes or bags, before being copied by dozens of imitators around the globe

\footnotetext{
${ }^{7}$ Both Wal-Mart and Target, to name the two most successful firms, have an extremely limited number of patents, which are moreover rather secondary as far as the sources of their productivity gains are concerned. In fact, if anything, Wal-Mart and Target have frequently found themselves victims of submarine patents attacks, as in the famous RFID World case of 2006 against both Wal-Mart and Target!
} 
selling something similar at $1 / 20$ or $1 / 30$ of their price - but it certainly is not the case with the less trendy houses that make up the bulk of the fashion and clothing business. When Zara copies the new jacket by Loewe maybe Loewe's designers have already moved on to some new products. But when it does the same, just to stick to Spain, with Roberto Verino or Adolfo Dominguez (two designers that aim at the middle portion of the market and whose collections do not change substantially from one season to the next) then it hurts their bottom line and it does so dramatically because a good fraction of the people who would be purchasing from Dominguez or Verino are also purchasing from Zara, while this is seldom the case for Loewe's selected clientele. Further, while a Dior bag can be easily spotted and it is hardly confused with its cheaper imitations, this is unlikely to be the case for a Dominguez jacket, hence the argument Foray advances to explain the lack of patents in this industry does not really apply to about $90 \%$ of the value added producing firms in this sector.

But this mistake in his analysis, while destructive in the specific case, is the least important from a general theoretical perspective. He may have got wrong the specifics of the fashion and design businesses purely because he does not know those industries well enough, still his general argument may be correct. In other words, it could still be true that those characteristics he identifies as specific of the high-end fashion business are exclusive to it and cannot be replicated in other, bigger and more important, sectors. A little reflection, though, shows that this is not the case and that, indeed, Foray's argument can easily be adapted to prove the opposite of what he likes to argue. Consider, for example, the music and movie businesses. Both follow fashion cycles that are determined and managed in ways not different from those of the clothing business. Both are characterized by super stars, stars, so-so stars, run-of-themill artists and so on. Both produce goods that have a very short economic life and are essentially voided of market value between six months to a year after their first release. In the case of popular music, in fact, one could easily repeat, almost verbatim, Foray's analysis of the market for high-end fashion goods and everything would go through smoothly. What would be the only difference? That, in this case, the good to be sold, from which lots of value added could be generated before it gets widely imitated, is not the CD or the recorded music per se - with modern technology and absent copyright these would probably be selling at near marginal cost after a couple of weeks, even if this would certainly not have been the case 10 years ago - but the live performances by the artists. As anyone familiar with the music business knows, revenues from live performances have been increasing dramatically during the last decade (as we predicted, on the basis of our theory of innovation, at the times of "Why Napster is right") and in many countries they now equal, as a share of total revenue, sales of recorded music. New lyrics may be copied and concerts imitated within a few months from when they are first released. But attending the latter and consuming the first version of the former is fashionable and worth a lot in the meanwhile, yielding substantial revenues to the innovators exactly like in the fashion business. After which, because imitators have come around, the creative artist has to move on to something new - the new lyrics and the new concert for the following year's tour - exactly like in the fashion business once again! 
The argument can be easily adapted to the case of movies and movie stars (yes, indeed, they may have to earn a living by acting live on stage sometimes, those among them that can at least ... but then, have you ever wondered what the opportunity cost is for a Hollywood Strip bartender to leave his/her job and become a theatre actor?) and of book writers (ask yourself: how many million dollars does the average good writer need to bear the burden of becoming famous?) The relevant analytical point that Foray misses is that impatience for consuming the new goods (whatever its reasons may be: social status, curiosity, boredom, rapidly decreasing marginal utility of the previous items, etcetera) is a common characteristics of all goods whose market value is determined by some "social fashion" cycle, hence of all the copyrighted goods, among other, and not just of fashion design! Said it otherwise: when applied with a bit of creativity and imagination - of which competitive entrepreneurs are certainly not as scarcely endowed as academics are - Foray's argument leads straightaway to the conclusion that copyright protection could be reduced to, say, one year, without affecting anything but the socially irrelevant riches of a few movie and music superstars! Strangely enough, Foray - like many other practitioners of the old and counter-factual "Schumpeterian" theories - fails to see this simple analogy and does not carry his otherwise nicely designed argument to its logical end. Which is: we can do well without copyright because the copyrightprotected sectors produce mostly positional goods, out of which substantial rents can be extracted through the sale of complementary goods, and for which innovation is a must even under competition.

A very similar argument could be developed for the case of Opens Source Software and other "communitarian" mechanisms of innovation sharing. Contrary to what analysts like Foray and other claim, these sectors do not rely on special norms of mutual interaction other than competition and profit seeking, plus the prohibition of claiming intellectual property over the products circulating within the sector. The "open knowledge regime", in the case of OSS, is not some particular institution supporting a special social norm but, rather, a kind of "local anti-trust" rule allowing competition to play its course, and nothing else. Programmers and firms operating within the OSS framework are profit maximizers, like everyone else, receiving their compensation mostly in a monetary form: salaries, profits, consulting fees, and so on. What makes the OSS sector thrives is that, because monopoly power is forbidden, participants are forced to innovate and the market value of the innovations is high enough that the competitive rents accruing to the innovator while her innovations are copied and replicated are large enough to cover for her opportunity costs of producing them. The rents come partly from the sale of the original copies of the innovation itself and partly from the sale of a complementary good (the programmer's expertise) which would not exist absent the innovation. That is, if one thinks of it, not so different from the way in which the financial consultancy and the medical professions, just to name two macroscopic examples, make a very good living. They both create new products and services that are frequently copied almost freely by competitors after a few initial copies have been sold at a relatively high price. But, while their innovations spread around by way of imitation, the financial consultant that first developed the new and successful product or portfolio rule and the medical doctor 
that came up with a new diagnostic technique or a new method to cure a disease, keep earning substantial rents for many years by selling their expertise (i.e. the innovation embodied in their human capital) to concerned clients and potential imitators likewise. Again, what in the eyes of the believer in the "Schumpeterian" model appears as a fringe and un-repeatable circumstance is revealed as nothing else but competition at works in one of its many real-world implementations.

Fact is: all the available evidence says that competitive markets innovate abundantly and new statistical evidence (e.g. Bessen and Hunt [2003] for the software industry, Correa [2010] for a large sample of sectors) is finally ${ }^{8}$ also starting to show that the rate of growth of productivity may in fact be decreasing, across industries and over time, as the degree of monopoly power, especially intellectual monopoly, increases. Our critics, therefore, may well be right when asserting that we are wrong, but the burden of the proof is on their shoulders. It is up to them to prove, through data and facts, that our examples are either distorted or irrelevant or special. Until that is done we can only remind the reader that, for various centuries, the very same negative and dismissive evaluation of the power of competition had been opposed to advocates of free trade. The history of the last century and a half is there to prove who was right and who was wrong in that particular debate 9

Therefore, while waiting for an empirical proof that competition harms innovation, let us move on to the issue that is most controversial: is it worth advocating the abolition of patents and copyright? Scientific studies of the current system agree that it is badly broken. Getting rid of it may therefore be a good idea. Still, one should pause. Realizing that intellectual monopoly may be akin to cancer, we recognize that simply cutting it all out at once poses problems. Since intellectual property laws have been around for a long while, we have learned to live with them. A myriad of other legal and informal institutions, business practices and professional skills have grown up around them and in symbiosis with them. Consequently, a sudden elimination of intellectual property laws may bring about collateral damages of an intolerable magnitude. What this argument suggests is that abolition must be approached by smaller steps, and that the sequencing of steps matters. Gradual reform is necessary both because of the need for other institutions, to reform in parallel, and also because it is a political necessity. The number of people prospering thanks to intellectual monopoly is large and growing. While some of them, such as movie stars, have accrued much wealth, for many others this is not the case. For many ordinary people intellectual monopoly has become another way of earning a living and, while most of them would be able to earn an equally good or even better living without it, many others need time to adjust. Further, and again in analogy

\footnotetext{
${ }^{8}$ The word "finally" should be qualified. George Stigler, in Stigler [1956], first provided evidence that this was indeed the case. The dominance of the "Schumpeterian" model, since then, has been so strong that pretty much no serious research had asked this question in a proper analytical and statistical format for more than 50 years. That competition could not generate innovation was a dogma nobody ever bothered to question.

${ }^{9}$ The reader may want to note that, theoretically, there are circumstances under which trade is detrimental to allocational efficiency and growth. Interestingly enough these are roughly the same circumstances under which competition is detrimental to innovation ...
} 
with trade barriers, while the number of people who would benefit from the elimination of intellectual monopoly is large and growing, the gain each one of them perceives as likely is small. In spite of the brouhaha surrounding the "pirating" of popular music and movies, the direct personal saving from copyright reduction or even abolition would not be substantial as music, movies and books are a tiny share of household consumption. In the case of medicines and software, consumers' potential saving may be more substantial but harder to perceive. Finally, and most importantly, if in the $1950 \mathrm{~s}$ or 1960s the average citizen of the world could hardly forecast the tremendous improvement in her standard of living that free trade would have brought about within thirty years, even harder it is now to perceive the incremental technological advances that a progressive elimination of intellectual monopoly could bring about in a couple of decades.

In summary, dismantling our intellectual property system requires facing a set of challenges that the literature on collective action has identified long ago as major barriers to reform. A few, well-organized and coordinated monopolists, on the one side, are bound to lose a lot if the protective barriers are lifted. A very large number of uncoordinated consumers, on the other side, would receive very small personal gains from the adoption of freer competition. For a long time then, the battleground is going to be one of competing ideas and theories aimed at convincing public opinion that substantial gains are possible from the elimination of intellectual monopoly. That is why, albeit reluctantly, we have chosen to conclude this brief summary of our position with a critical discussion of some of the criticisms a particularly distinguished defender of intellectual property has levied against our book.

\section{Confused criticisms}

Scherer [2009] contains a very negative review of our book, which (for a variety of rather obvious reasons) we had chosen to ignore until it turned out that, possibly for the prestige associated to the name of Scherer in the field of industrial organization, it was being widely used to dismiss our position outright without ever addressing the substantive issues it raises. Last, but not the least, this is what Dominique Foray does in his contribution to this volume where, after a summary description of one of our models, he writes

"Much could of course be said about the approach of Boldrin and Levine, especially their carelessness and lack of interest concerning empirical data (see the very severe criticism of Scherer (2009) in this connection). For instance, applied microeconomists strongly disagree that there is no evidence as to unpriced spillovers; the whole geographically mediated patent citation literature has built an extensive base of evidence regarding the existence of these spillovers. The theoretical argument of Boldrin and Levine is therefore correct but under conditions (absence of unpriced spillovers) that make it a special case where the intellectual asset is endowed with a property of natural excludability (particularly linked with its strong tacit dimension, Foray, 2009)."

There are three propositions here and they are all three embarrassingly incorrect. Let us start from the last one. The assumption of complete, or natural, excludability is irrelevant to the argument developed in our paper "Perfectly 
Competitive Innovation" (Boldrin and Levine [2008], see also Boldrin and Levine [2004b, 2005a]) as one can quickly figure out by simply reading it, as it contains a discussion of the case in which positive external effects are present. Again, the issue here is one of (net discounted value of) appropriated rents versus opportunity cost of innovation. The presence of un-priced external effects makes a difference only insofar as it implies a below optimal effort (about which, in a line or two) but it does not imply that the competitive rents accruing to the innovator would not be enough to give her the incentive to innovate! Real externalities, obviously, implies a socially suboptimal effort but, equally obviously, their presence suggest that either a tax or a subsidy or a prize should be the appropriate public intervention, not the concession of a legal monopoly! Moral: as far as economic theory is concerned, the presence or absence of externalities is completely orthogonal to the debate about intellectual property.

As for the actual presence of substantial un-priced externalities under competition, which Foray takes for granted, we can only say two things. If there were externalities, patents would certainly not "price" them efficiently, hence the deadweight loss monopoly induces would simply be added to the inefficiency due to the external effect. Moreover, in the very many studies we are aware of, there is no clear empirical evidence of the allegedly widespread external effect and, surprisingly, Foray himself provides no reference whatsoever to support his claim, not even one. But these are secondary matters, from a scientific view point. The relevant ones are other: to the extent imitation is the simplest and most frequent form of technological adoption, which it is, there are natural external effects in the real world. As a matter of theory, any competitive model of technological change allowing for imitation will automatically yield a suboptimal equilibrium when everyone imitates everyone else. This is not only plain and obvious, it is also well understood and the open problems are elsewhere. (1) Quantitatively speaking, how large are those externalities in relation to the overall cost of innovation/imitation and to the overall social value of an innovation? (2) Is the allocation that obtains at a competitive equilibrium with imitation better or worse, from a social view point, than the one that obtains at a monopolistic equilibrium of the same economy? Hic sunt leones, which we very much doubt applied microeconomists working in the "Schumpeterian" tradition have even discovered to exist, let alone face and tame.

Finally, we come to the most painful proposition, according to which the review by Scherer [2009] proves how careless and without interest for empirical data our whole research is. The latter statement could be easily dismissed on the ground that about 7/10 of our book, and a number of our papers in this field, are all about data and historical facts. It is apparent that neither Foray nor Scherer have spent much time reading either the book or our papers because, had they done so, they would at least criticized our empirical findings showing how inconsistent they are; or maybe not. In any case, because Scherer's review is invoked as the only evidence proving the sloppiness and lack of empirical substance of our research we have no alternative but face Scherer's criticisms, one by one. It is not going to be nice, and we apologize from the start. 
Scherer's first criticism is that we are apparently so confused to believe that the "great man", as he calls his friend Joe Schumpeter, was actually called Jason and his great book - in the eyes of Scherer: in ours it is one of the most confusing pieces a social scientist ever produced, after the General Theory - was published in 1943 instead of 1942. He fails to mention that, in the body of our book, the great man is repeatedly mentioned by his full name, Joseph, and that "Jason" is clearly and editorial typo introduced in the index of names, together with the wrong date. Having chosen to start his review with this kind of remarks is a clear indicator of Scherer's attitude, as are his complains because, in a bibliography that covers more than 300 titles, about $20 \%$ of them (including all the USPO documents, the Supreme Court sentences, and so on) are referenced as available through the internet!

He then claims that we misrepresent the substance of the survey by Cohen et al. (2000) because "It makes a huge difference to say, as Boldrin and Levine do, that only about one-third of respondents believed that patents were effective, instead of reporting accurately that on average patents were effective in appropriating benefits for $35 \%$ of the innovations made by respondent companies." Too bad he fails to point out that, just above the lines he quotes, we explain quite clearly what the survey is about, thereby making obvious what the word "firms" means here. Beside, Scherer fails to explain where the huge difference is supposed to be in this context: in both cases it remains true that only in, roughly, one case out of three patents are effective in appropriating benefits from innovation. Carried away by the preposterous nature of his criticism, Scherer also add that this survey constitutes "a bulwark of their argument" (one page and seven lines, for two surveys in fact, in a book of 270 pages) and that "From this error, they go on to claim that the marginal stimulus to $R \& D$ of patents is zero" which is a figment of his imagination, including the italicizing of the word "marginal", as we never developed such argument anywhere in the book. Interestingly, in the third edition of his textbook (Scherer [1990]) we read "This conclusion is supported by the findings from several surveys of $R \& D$ executives, revealing quite uniformly that in most industries, patents are not very important compared to other incentives for innovation. In the most recent and comprehensive effort, Levin et al. asked 650 U.S. R\&D executives to evaluate on a scale of from 1 ("not at all effective") to 7 ("very effective") the effectiveness of alternative means of protecting the competitive advantages from new and improved products and processes. Averaging across 130 industries the scores on six questionnaire items were as follows: [table.] ..." The survey Scherer quotes here, which we also mention in the book, is an earlier one but its aims and findings are completely coherent with the later one. It is interesting to note how Scherer, when not reviewing books by authors he does not like, uses the same sloppy language he finds so mistaken in other. In his textbook he goes on talking about "industries", "R\&D executives" and the same language is used to describe shortly after Mansfield [1986] survey to conclude, surprisingly, that "Thus, a world without patents quite clearly would not be a world without innovation. Other incentives for innovation would fill most gaps. Some inventions would be lost, [... small firms will need protection, etcetera]. "10

${ }^{10}$ Pages 629-630. 
Things get even more interesting as Scherer decides to take up our theory, which he must have considered very carefully given the Mickey Mouse rendition he provides ("They present a naive but serviceable supply and demand model") and which, surprise surprise, he had anticipated long ago. He writes, in fact: "Both arguments, supported by numerous anecdotes, have roots in an extensive prior literature not cited by Boldrin and Levine. Except for some supporting evidence, all of the essential elements had emerged in time for the survey in Chap. 16 of the second (1980) edition of my industrial organization textbook." Well, we went and checked it out. In the third edition (1990) of the same textbook - the latest available in case the interested reader wanted to double check - the chapter in question is numbered 17 and is nearly identical to Chapter 16 of the second edition. We searched long and hard in that chapter (and in the rest of the book, to be honest) and here is what we have found. In the section titled "The Logic of Patent Protection" between page 621 and page 624, Scherer explains his basic model, which is the very standard one and that we have already duly criticized before, in section 3 . Here are some key excerpts:

"Suppose, however, that there were no patent protection and no other barriers to the imitation of the innovator's invention. Then a scenario like the one shown in panel (b) of Figure 17.1 might unfold. Soon after the new product appears, competing firms will introduce their imitating products, squeezing the demand schedule left for the original innovator to D2. With less residual demand, the innovator must derive a new marginal revenue function $M R 2$ and set a new, lower price OP2, which yields profit rectangle $P 2 B Y M$ barely covering the innovator's $R \& D$ debt service cost. However, the imitator firms may have had to incur little of no $R \& D$ cost on their own, "free riding" on the innovator's R\&D and thus, with unit costs of only OM [the same marginal cost the innovator faces], they will realize supra-normal profits at price OP2. More competitors will be drawn in by this price and profit lure, squeezing the innovator's residual demand curve further to D3. The innovator must reoptimize again [...] profit [...] now smaller than the continuing $R \& D$ debt service obligations. If this diffusion process were to unfold rapidly and if the innovator correctly foresaw its course, the innovator would perceive that its $R \& D$ costs will not be recouped and would therefore choose not to invest in the $R \& D$ [...] Pursuing the analysis a step further, we see a kind of dilemma. If the R\&D investment were incurred and the innovation made, imitative entry might, absent patent protection, continue until the price is driven all the way down to the competitive level, ignoring the innovator's front-end costs - that is, to OM [the marginal cost, apparently common to both imitators and innovator, and constant, n.d.r.] [...] The technological well will run dry. The patent system makes a deliberate tradeoff, accepting during the patent grant's life dead-weight surplus losses in order to ensure that the new products and processes,, along with the surpluses they create, will not be discouraged by fear of rapid imitation."

Not only this is the exact opposite of our model but also, as the reader may have noticed, this is a verbal rendition of the same naïve and inconsistent (but serviceable?) traditional model we discussed in Section 3 . The one in which, if you are not careless and look carefully, the logical implications are the opposite of those Scherer wants to reach because, under his assumptions, there will never be any imitation in the unique sub-game perfect equilibrium of his model. Never mind, let us continue searching. At this point we find the paragraphs, already mentioned above, in 
which Scherer describes the results of the "Yale Survey", which is introduced, on page 628, with this statement "As a result [of various factors delaying imitation, n.d.r.], the profit expectations associated with a prospective innovation may be sufficient to warrant going ahead even when no patent protection is anticipated." Could this single statement be "all the essential elements" Scherer mentions in order to dispose of our "serviceable model"? It seems to be the case, because after illustrating the Yale Survey he moves on to a section titled "The Links between Market Structure and Innovation", where oligopolistic competition is discussed to reach the conclusion (page 637) "We find therefore a clash of structural propensities, giving rise to a dualism in the links between market structure and incentives for innovation. Up to a point, increased fragmentation stimulates more rapid and intense support of $R \& D$. [...] But when the number of firms becomes so large that no individual firm can appropriate quasi rents sufficient to cover its $R \& D$ costs, innovation can be slowed or even brought to a halt." This, most certainly, is not an anticipation of what we have been claiming, right or wrong that it may be. Further down things get even worse, but they also get clearer. In the subsection titled "Dynamics and Welfare Implications" (pp. 637-644), he uses a model by Yoram Bazel to reach the following conclusions (pp. 639-640), which clearly illustrate what Scherer considers to be a proper characterization of competition: "Barzel invokes here the classic equilibrium definition: competition is characterized by such free entry that expected profits (after covering fixed $R \& D$ costs) are zero. This can only occur at the break-even point [...] Just how the competitive process evolves to achieve this zero profit equilibrium need not concern us in detail yet. It cannot be through postinnovation price competition, for a perfect patent permits monopoly pricing then. So the competition is at the preinnovation stage, for example, in Barzel's original schema, as a single firm preempts its less bold rivals with and $R \& D$ project conducted so early that its costs equal discounted quasi rents." He continues on to find that competition in the Barzel's sense innovates at the optimal rate only by "happenstance" and, after a long and contorted discussion that relies heavily on externalities, Scherer concludes (pp. 642) that "Profitable oligopoly is most apt to sustain an innovation pace preferable to that of monopoly and competition". The issue here is neither if the models Scherer uses are interesting and appropriate nor if his conclusions are empirically supported. The issue here is that there is no actual evidence, in his textbook, that the priority claim he makes in his review of our book is based on anything other than his own wishful thinking.

The rest of the review has the same "quality", and one would be tempted to stop here were not because a couple of more interesting facts can be noted by moving forward. The bulk of Scherer's review is dedicated, in fact, to Chapter 9 of our book, which aims at briefly discussing the implications of our theory for the pharmaceutical sector. Scherer's discussion, here, is distinctively bipolar. On the one hand, he complains for our lack of attention to studies carried out various decades ago and characterizing a pharmaceutical sector quite different from the one we are facing today, while complaining for a sequence of alleged "mistakes" that he neither 
documents nor explains but simply states as such. ${ }^{11}$ On the other, he seems to agree with the substance of our conclusions (he misses completely the economics behind our discussion of "me too drugs" and even the conclusions we reach, but we are ready to blame it on our obscure writing style and not on his lack of attention) but is irritated by the fact that we do not quote a certain book (Angell [2004]) which, admittedly, we discovered only after having completed ours and that, nevertheless, makes in many more details the very same points we actually make in our short chapter with regard to the drugs industry. Matter of fact, an earlier article by the same author is quoted and used in Chapter 9!

One wonders, then, about the motives leading Scherer to write such a negative review of our book, given the absolute lack of substantive criticisms he is capable of raising and, at the same time, why such a pitiful collection of snotty and unsubstantiated remarks would become an excuse not to address the substance of the matter on the part of other researchers. While we do not have an answer for the latter question, we may have found one for the first: F. M. Scherer, apparently, did not review our book but something else. According to the title of his review he is concerned with a book titled "Against Intellectual Property", while ours is titled "Against Intellectual Monopoly". Talk about "carelessness".

\section{Conclusions}

For centuries, the cause of economic progress has been identified with that of free trade. In the decades to come, sustaining economic progress will depend, more and more, upon our ability to progressively reduce and eventually eliminate intellectual monopoly. As in the battle for free trade, the first step must consist in destroying the intellectual foundations of the obscurantist position. Back then the mercantilist fallacy taught that, to become wealthy, a country must regulate trade and strive for trade surpluses. Today, the same fallacy teaches that without intellectual monopoly innovations would be impossible and that our governments should prohibit parallel import and enforce draconian intellectual monopoly rules. We hope that we have made some progress in demolishing that myth.

\footnotetext{
${ }^{11}$ Had Scherer spent an hour or two explaining what those mistakes were, and providing references to the correct calculations, one could attempt a reply that is instead impossible in front of statements of the type "you are wrong because I say so".
} 


\section{References}

Angell, M. [2004], The truth about the drug companies. New York: Random House.

Bessen, J. and R. M. Hunt [2003], “An Empirical Look at Software Patents”, mimeo, May; available at http://opensource.mit.edu/papers/bessen.pdf. Abridged version published in Journal of Economics \& Management Strategy 16(1), Spring 2007, 157-189.

Boldrin, M. and D. K. Levine [2004a], "Rent Seeking and Innovation", Journal of Monetary Economics 51: 127-160.

Boldrin, M. and D. K. Levine [2004b], "2003 Lawrence Klein Lecture: The Case Against Intellectual Monopoly”, International Economic Review 45: 327-350.

Boldrin, M. and D. K. Levine [2005a], "The Economics of Ideas and Intellectual Property", Proceedings of the National Academy of Sciences 102: 1252-56.

Boldrin, M. and D. K. Levine [2005b], "IP and Market Size", mimeo, www.econ.umn.edu/ mboldrin//Research/Current_Research/innovation.html

Boldrin, M and D.K. Levine [2008], "Perfectly Competitive Innovation", Journal of Monetary Economics, 55: 435-453.

Boldrin, M., and D. K. Levine [2009] , "A Model of Discovery." American Economic Review, 99(2): 337-42.

Cohen, W. M., Nelson, R. R., \& Walsh, J. [2000], "Protecting their intellectual assets: Appropriability conditions and why US manufacturing firms patent (or not)." National Bureau of Economic Research, working paper no. 7552.

Correa, J. [2010], "Innovation and Competition in a Memory Process", Discussion paper ISSN 0966-4246, University of Southampton.

Hirshleifer, J. [1971], “The Private and Social Value of Information and the Reward to Inventive Activity" The American Economic Review 61, 561-574.

Jaffe, A.B. [2000], "The U.S. Patent System in Transition: Policy Innovation and the Innovation Process", Research Policy 29, 531-557.

Kanwar, S. and R. Evenson [2003], "Does Intellectual Property Protection Spur Technological Change?" Oxford Economic Papers 55,235-264

Lerner, J. [2009], "The Empirical Impact of Intellectual Property Rights on Innovation: Puzzles and Clues." American Economic Review, 99(2): 343-48.

Lo, S-T. [2004], "Strenghtening Intellectual Property Rights: Experience from the 1986 Taiwanese Patent Reforms", mimeo, UCLA, Dept. of Economics. Available on line at http://www.international.ucla.edu/article.asp?parentid=10985

North D. C. [1981], Structure and Change in Economic History, Norton.

North, D. [1991], Institutions, Institutional Change and Economic Performance, Cambridge University Press

Scherer, F. M. [1990], Industrial market structure and economic performance. Boston: Houghton Mifflin Company. 
Stigler, G. J. [1956], "Industrial Organization and Economic Progress," in The State of the Social Science edited by Leonard D. White, University of Chicago Press, 269-282.

David K. Levine and Michele Boldrin are professors of economics at Washington University in S. Louis, and the authors of "Against Intellectual Monopoly." 